\title{
DAVID BLOOR E 0 “PROGRAMA FORTE” DA SOCIOLOGIA DA CIÊNCIA: UM DEBATE SOBRE A NATUREZA DA CIÊNCIA
}

\author{
NEUSA TERESINHA MASSONI ${ }^{*}$ \\ https://orcid.org/0000-0002-1145-111X \\ MARCO ANTONIO MOREIRA $\|^{* *}$ \\ https://orcid.org/0000-0003-2989-619X
}

RESUMO: Este texto apresenta uma visão introdutória à sociologia do conhecimento de David Bloor, chamando a atenção a que o debate (sociológico ou não) em torno da natureza da ciência não terminou e que, nesta visão, a sociologia assume uma característica comum à própria ciência, isto é, não tem perguntas nem respostas finais. São abordados os quatro princípios-fundamentais do que Bloor chama de "programa forte" da sociologia do conhecimento, segundo o qual ela deve ser causal, imparcial, simétrica e reflexiva. Além desses princípios, são discutidas as posições de Bloor em relação a conceitos como empirismo, verdade e realidade, experiência e crença, e epistemologias como as de Popper, Kuhn, Durkheim e Latour. Algumas implicações desta visão para a educação científica são também discutidas.

Palavras-chave: Sociologia do conhecimento. Programa forte. Natureza da ciência.

\section{DAVID BLOOR Y EL "PROGRAMA FUERTE" DE LA SOCIOLOGÍA DE LA CIENCIA: UN DEBATE ACERCA DE LA NATURALEZA DE LA CIENCIA}

RESUMEN: Este texto presenta una visión introductoria a la sociología del conocimiento de David Bloor, señalando que el debate (sociológico o no) acerca de la naturaleza de la ciencia no ha terminado y que, en esta visión, la sociología asume una característica común a la propia ciencia, es decir, no tiene preguntas tampoco respuestas finales. Se abordan los cuatro principios fundamentales de lo que Bloor llama de "programa fuerte" de la sociología del conocimiento, de acuerdo con el cual ella debe

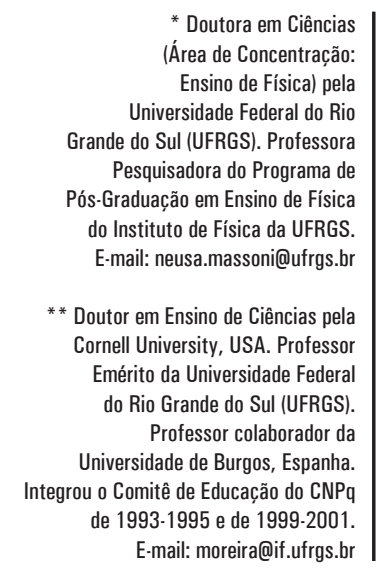

* Doutora em Ciências Ârea de Concentração: Ensino de Física) pela nde do Sul (UFRGS). Professora Pesquisadora do Programa de Pós-Graduação em Ensino de Física do Instituto de Física da UFRGS E-mail: neusa.massoni@ufrgs.br

Doutor em Ensino de Ciências pela Cornell University, USA. Professor Emérito da Universidade Federal Rio Grande do Sul (UFRGS). Professor colaborador da o Comitê de Educação do CNPq E-mail: moreira@if.ufrgs.br

\footnotetext{
' Universidade Federal do Rio Grande do Sul, Instituto de Física, Programa de Pós-Graduação em Ensino de Física, Porto Alegre, RS - Brasil.

" Universidade de Burgos, Burgos - Espanha.
} 
ser causal, imparcial, simétrica y reflexiva. Además de esos principios, se discuten las posiciones de Bloor en relación con conceptos como empirismo, verdad y realidad, experiencia y creencia, y epistemologías como las de Popp, Kuhn, Durkheim y Latour. Se discuten también algunas implicaciones de esta visión para la educación científica.

Palabras clave: Sociología del conocimiento. Programa fuerte. Naturaleza de la ciencia.

\section{DAVID BLOOR AND THE "STRONG PROGRAM" OF THE SOCIOLOGY OF SICENCE: A DEBATE ON THE NATURE OF SCIENCE}

ABSTRACT: This paper presents an introductory view of David Bloor's sociology of knowledge, pointing out that the debate (sociological or not) on the nature of science has not ended yet and that, in this view, sociology has a feature typical of the science, that is, there are no final questions and answers. According to the four principles of what Bloor calls "strong program" of the sociology of science it must be causal, impartial, symmetric and reflexive. In addition to these principles, Bloor's positions regarding concepts such as empirism, truth, and reality, experience and belief, and regarding epistemologies such as those of Popper, Kuhn, Durkheim and Latour are approached. Some implications of this view for scientific education are also discussed.

Keywords: Sociology of knowledge. Strong program. Nature of science. 


\section{INTRODUÇÃO}

Perceber o desenvolvimento científico como uma complexa rede científica-política-social é um requisito fundamental para evitar o risco de assumir, e até mesmo passar aos estudantes, visões histórico-epistemológicas inadequadas, anacrônicas, de linearidade temporal, de heroificação dos cientistas, baseada de "descobertas", o que, há muito, é criticado pela "historiografia whig" (MARTINS, 1990; FORATO et al., 2011). Este tipo de simplificação, além da atribuir pouca importância às controvérsias científicas e erros que a ciência precisou superar, muitas vezes é adotado inadvertidamente com o fim de tornar aulas de ciências mais atrativas. Este tipo de estratégia precisa ser problematizado se quisermos formar cidadãos críticos. Há muito se defende que ensinar ciências requer arranjar situações que favoreçam a aquisição do conhecimento científico e também aprimorem ideias e concepções epistemológicas dos educandos. Alguns autores (e.g. BERLAND et al., 2016) defendem que é fundamental engajar os estudantes em "práticas científicas" (por exemplo, manejo de variáveis, construção de produtos, etc.) associadas a ideias epistemológicas (que os auxiliem a perceberem, por exemplo, porque fazer, como fazer, que caminhos tomar, quais são os objetivos, etc.), de forma que o ensino se alinhe aos objetivos e abordagens epistêmicas da construção do próprio conhecimento científico. A ideia central é fazer com que os estudantes aprendam ciências e também reflitam sobre a natureza da ciência.

Nessa linha, o presente texto tem dois objetivos: sintetizar a visão sociológica de David Bloor e, fazendo-o, busca-se instrumentalizar professores de ciências para que se sintam mais confortáveis em discutir diferentes vieses do processo de construção da ciência e, ao mesmo tempo, reflitam suas práticas didáticas. Este último aspecto é retomado nas considerações finais.

David Bloor, sociólogo, escocês, nascido em 1942, professor na Universidade de Edimburgo, começou sua vida acadêmica pelo estudo da Filosofia e Psicologia, mas faz uma abordagem sociológica sobre o estudo das Ciências - que ele chama de "programa forte" da sociologia do conhecimento. Nesse sentido, Bloor é uma das figuras mais proeminentes da Sociologia da Ciência e isso fica expresso já no primeiro parágrafo do seu livro mais conhecido, intitulado Conhecimento e Imaginário Social, em que ele coloca a pergunta "a sociologia da ciência pode investigar e explicar o conteúdo e a natureza do conbecimento cientifico?" (BLOOR, 2009, p. 15). Sua resposta é positiva. Afirma ele que os sociólogos foram sempre muito tímidos ao limitar seus estudos a aspectos institucionais e a fatores externos às Ciências, deixando intocada a natureza mesma do conhecimento científico. Atribui tal hesitação, não à falta de teorias e métodos, mas à falta de vigor dos sociólogos para proceder a um escrutínio do conhecimento científico. Coloca que "o objetivo deste livro será o de combater tais argumentos e inibições" (ibid., p. 17).

Assim, Bloor apresenta as bases do "programa forte" da Sociologia do Conhecimento e investe fortemente no entendimento naturalista do conhecimento humano, inclusive do conhecimento científico. 


\section{O “PROGRAMA FORTE” DA SOCIOLOGIA DO CONHECIMENTO}

O conhecimento científico pode ser tomado como um fenômeno natural pelo sociólogo. Nessa linha, destaca ele, conhecimento étudo aquilo que aspessoas consideram conhecimento (ibid., p. 18). Consiste nas crenças que as pessoas sustentam com confiança e com as quais levam suas vidas. Contudo, o sociólogo está interessado especialmente nas crenças consideradas como certas, institucionalizadas, investidas de autoridade por grupos de pessoas. Conhecimento, portanto, não são as crenças individuais e idiossincráticas, mas é aquilo que é endossado coletivamente. É o caso tanto das ciências quanto das culturas. Investigar as causas das variacõoes das ideias das pessoas sobre o funcionamento do mundo, quão estáveis elas são, como o conhecimento é criado, compartilhado, organizado é de fundamental interesse para a Sociologia do Conhecimento. Para Bloor, as explicações devem satisfazer à condição de generalidade, isto é, devem ser aplicadas seja a crenças verdadeiras ou falsas e precisam dar conta das regularidades, assim como ocorre na Mecânica em Física, na Fisiologia, no movimento dos corpos celestes em Astronomia, etc.

Para incorporar os mesmos valores assegurados a outras disciplinas científicas, Bloor afirma que a sociologia do conhecimento deveria aderir a quatro princípios fundamentais:

1. Ela deverá ser causal, ou seja, interessada nas condições que ocasionam as crenças ou os estados de conhecimento. Naturalmente, haverá outros tipos de causas além das sociais que contribuirão na produção de uma crença.

2. Ela deverá ser imparcial com respeito à verdade e à falsidade, racionalidade e irracionalidade, sucesso e fracasso. Ambos os lados dessas dicotomias irão requerer explicação.

3. Ela deverá ser simétrica em seu estilo de explicação. Os mesmos tipos de causa deverão explicar, digamos, crenças verdadeiras e falsas.

4. Ela deverá ser reflexiva. Seus padrões de explicação terão que ser aplicáveis, a princípio, à própria Sociologia. Assim como a condição de simetria, essa é uma resposta à necessidade da busca por explicações gerais. (ibid., p. 21).

Estes princípios de causalidade, de imparcialidade, de simetria ${ }^{1}$ e de reflexividade definem o que ele chama de "programa forte da sociologia do conhecimento" e estão amalgamados com os traços científicos colocados por Durkheim (1938), Mannheim (1936) e Znaniecki (1965), que são os sociólogos mais citados por Bloor. Para mostrar a plausibilidade de seu programa forte ele discute e combate algumas críticas e objeções colocadas à Sociologia do Conhecimento.

\section{A DEFESA DO “PROGRAMA FORTE” DA SOCIOLOGIA DO CONHECIMENTO}

Para Bloor existem objeções à ideia de que o conhecimento dependa de perspectivas sociais e são esses argumentos equivocados que ele busca combater. 
Destaca que uma importante objeção à sociologia do conhecimento tem origem na convicção de que quando nos comportamos de forma racional e lógica, nossas ações dispensam explicações causais. A lógica seria constituida de um conjunto de conexões entre premissas e conclusões, e nossas mentes poderiam seguir essas conexões (BLOOR, 2009, p. 22). Nessa linha, enquanto alguém fosse razoável, as próprias conexões poderiam oferecer a explicação para suas crenças. Nos casos em que ocorrem lapsos, erros e enganos, estes sim seriam devidos à interferência de fatores externos e exigiriam uma explicação causal. Para Bloor, essa abordagem pode ser resumida na afirmação de que nada leva as pessoas a fazer coisas corretas, mas algo perpetra, ou causa o que dá errado (p. 23). Em suma, a racionalidade e a verdade dispensariam explicações enquanto o erro e a irracionalidade invocam causas, psicológicas ou sociais.

Quando essas convicções são aplicadas ao campo da atividade intelectual, argumenta Bloor, têm o efeito de tornar o corpo de conhecimento um domínio autônomo, autoexplicativo e autopropelido, isto é, os procedimentos, métodos, padrões e resultados da atividade intelectual explicariam a própria atividade. ${ }^{2}$

Neste ponto Bloor critica a filosofia da ciência de Lakatos, que propõe uma abordagem da ciência em que a metodologia científica é escolhida, isto é, a heurística positiva e negativa indicam quais passos ou linhas são racionais para apoiar o trabalho científico. Isto sugere, aponta Bloor, que a ciência seria um processo que se desenvolve segundo seus próprios princípios metodológicos, sendo racional segundo essa filosofia. Lakatos (1993) chama a isto de "história interna". Mas como ela não pode explicar toda a diversidade da prática científica, Lakatos admite que a história interna deva ser complementada por uma "história externa”. Para Bloor, Lakatos tem a pretensão de mostrar que a história interna, autossuficiente e autônoma, explica as reconstruções e explicações racionais e tem prioridade sobre a história externa ou sociológica, que seria secundária, já que seus problemas de pesquisa são definidos pela história interna. As explicações sociológicas ou externalistas estariam confinadas ao que há de irracional na ciência (por exemplo, as crenças místicas de Kepler sobre a majestade do Sol). A essa postura Bloor coloca seguinte questão: o que incita o correto funcionamento interno de uma atividade intelectual se a busca de causas psicológicas ou sociológicas só é considerada apropriada em caso de irracionalidade ou erro? (BLOOR, 2009, pp. 25-26).

A teoria que sustenta tais ideias é uma concepção finalista, que Bloor chama de modelo teleológico, segundo o qual a verdade, a racionalidade, a validade seriam nossos fins naturais e a direção mesma de tendências naturais que possuímos. Em outras palavras, somos seres racionais e naturalmente abrimos caminho para a verdade sempre que ela está ao nosso alcance. Assim, nossas crenças racionais não demandariam comentários especiais, mas sempre que o progresso autopropelido para a verdade sofresse desvios, fosse impedido ou houvesse erros, então sim, as causas deveriam ser localizadas e explicadas. As causas sociais seriam identificadas aos fatores extrateóricos, enquanto a atividade intelectual seria governada pela lógica interna teórico-metodológica.

Para Bloor, o modelo teleológico ou finalista viola os princípios do "programa forte da sociologia do conhecimento", pois a causalidade (seu "modelo causal") pode ser indicada apenas para os erros; viola também os princípios da simetria e da imparcialidade, pois dado que uma explicação (para ser aceita) depende de 
avaliações prévias, exige-se uma avaliação prévia da racionalidade de uma crença antes que seja decidido se ela pode ser considerada autoexplicativa ou se é necessária uma teoria causal.

Sustenta Bloor que o modelo causal em confronto ao modelo teleológico e afirma que representam, portanto, alternativas programáticas que se excluem mutuamente. Com efeito, eles são dois pontos de vista metafísicos opostos (BLOOR, 2009. p. 27). Contudo, ele não acredita que seja preciso tomar um dos modelos como falso para poder aceitar o outro, pois considera improvável que um argumento decisivo possa ser apresentado a priori para provar a verdade ou falsidade dessas alternativas metafísicas. Para ele, a sociologia do conhecimento não tem o objetivo de eliminar o ponto de vista rival, mas sim de se separar dele e assegurar que sua própria casa esteja logicamente em ordem, pois o "programa forte" também anseia por um tipo específico de generalidade, por uma concepção do mundo natural como moralmente vazio e neutro.

Portanto, em relação à moralidade, ele também insiste em dar certo papel à natureza, ainda que negativo. Isso quer dizer que o programa representa como natural àquilo que pressupõe. (ibid., p. 29).

Para o autor, o que está na base do modelo teleológico é que a causalidade está associada ao erro e à limitação; isto representa uma forma extrema de assimetria e uma forte objeção ao "programa forte", que busca estilos simétricos de explicação.

Outra objeção à sociologia do conhecimento é o argumento empirista, pois se poderia alegar que o uso desimpedido de nossa percepção e de nosso aparelho sensório-motor produz crenças verdadeiras, enquanto as influências sociais produzem distorções de nossas crenças. Isto exalta a experiência e o uso de nossos sentidos como fonte de conhecimento testado, ou seja, conhecimento de primeira mão e transforma as interações sociais em algo que corrompe o verdadeiro conhecimento, tornando o espírito científico uma presa fácil de histórias supersticiosas, mitos e especulações. Assumir uma postura assim é, para Bloor, aceitar, uma vez mais, que a sociologia do conhecimento é uma sociologia do erro, da crença ou da opinião, o que se aproxima muito dos conselhos de Francis Bacon como o de evitar os ídolos do mercado e do teatro. Nessa concepção empirista Bloor vê dois problemas: 1) seria errado presumir que o funcionamento de nossos sentidos sempre produza conhecimento, pois eles produzem conhecimento e erro de um modo igualmente natural e através da operação do mesmo tipo de causa. Por exemplo, ansiedade, fome, estresse são causas igualmente correlacionadas a crenças verdadeiras e falsas; nossos mecanismos psicológicos do aprendizado operam em um arranjo ótimo de funcionamento, mas quando saem do foco produzem erro; 2) o empirismo leva ao caráter individualista. Bloor afirma que muito pouco do conhecimento humano é construído pela experiência sensorial individual com o mundo. Adverte que essa abordagem psicológica não leva em consideração um componente importante, o componente social da ciência.

Ele afasta o argumento empirista da seguinte forma:

Desse modo, o conhecimento da nossa cultura, tal como é representado pela nossa ciência, não é o conhecimento de uma realidade que qualquer indivíduo pode 
experienciar ou aprender por si próprio. Ele é o que nossas teorias mais comprovadas e nossos pensamentos mais instruídos nos dizem ser, não importando o que indiquem as aparências. Ele é uma história tramada das insinuações e vislumbres que acreditamos que nossos experimentos nos contam. O conhecimento, portanto, é mais bem igualado à cultura que a experiência. (ibid., p. 33).

Se aceitarmos esta definição de "conhecimento", a distinção entre verdade e erro não estaria associada à separação entre experiência individual (ótima) e influência social. Para Bloor, no amálgama das experiências e crenças socialmente mediadas que cria o conteúdo de uma cultura, essa distinção é uma discriminação entre misturas rivais de experiência e crença, dois ingredientes que ocorrem tanto para crenças verdadeiras como para as falsas. É nisso que consiste, para ele, o estilo simétrico de explicação, pois invoca os mesmos tipos de causas.

Contudo, sua preocupação centra-se em refutar as objeções à sociologia do conhecimento (em abrandar o abismo entre as ciências naturais e sociais) e não em repudiar o empirismo. Ao contrário, defende que o empirismo tem virtudes importantes e pode fornecer intuições fundamentais à sociologia do conhecimento.

\title{
A CIÊNCIA SOCIAL E A NATUREZA DA CIÊNCIA
}

Para Bloor, o sociólogo tem por objetivo desenvolver teorias conjeturais com base em estudos de caso empíricos e históricos e testá-las diante de outros estudos. Contudo, alerta que o conhecimento limitado e as vastas oportunidades para o erro podem levar a previsões falsas. Isto, porém, em nada deve desencorajar o trabalho do sociólogo, pois, lembra ele, o próprio Karl Popper (1980) via a ciência como um panorama sem fim de conjeturas refutadas, o que não intimida o cientista natural. Então, não há razão para pensar que esse efeito se aplique às ciências sociais. Para ele, a busca de regularidades e leis do mundo social é uma questão de pesquisa empírica, não de debate filosófico.

\begin{abstract}
A busca de leis e teorias na sociologia do conhecimento é absolutamente idêntica em relação aos procedimentos de qualquer outra ciência. (...). Investigações empíricas localizarão eventos típicos e recorrentes. Tais investigações poderão, elas próprias, ter sido suscitadas por alguma teoria anterior, pela violação de uma expectativa tácita ou por necessidades práticas. Deve-se, em seguida, inventar uma teoria que explique a regularidade. Ela formulará um princípio geral ou um modelo a fim de dar conta dos fatos. (...). A teoria ou o modelo poderão, por exemplo, explicar não apenas o porquê de uma regularidade empírica ocorrer, mas também por que, às vezes, não ocorre. Ela poderá servir de guia para as condições necessárias à regularidade e, com isso, para as causas de desacordo e variação. (BLOOR, 2009, p. 40).
\end{abstract}

Percebe-se que uma teoria, na sociologia do conhecimento, pode exigir pesquisas empíricas refinadas que poderão resultar na rejeição ou modificação da própria teoria, assim como ocorre com as demais ciências. Bloor ilustra isto com o seguinte caso: tem sido notado que as disputas de prioridade sobre descobertas são um traço comum da ciência (por exemplo, a disputa entre Newton e Leibniz sobre a invenção do 
cálculo; entre Cavendish, Watt e Lavoisier sobre a composição química da água, etc.). Isto resulta de uma observação empírica que pode ser expressa na generalização de que "descobertas" provocam disputas de prioridade. Mas isto, argumenta Bloor, pode ser considerado irrelevante para a verdadeira natureza da ciência. Por outro lado, podemos querer buscar uma explicação. Por exemplo, podemos propor que a ciência funciona como um sistema de trocas, que "contribuições" são comutadas com reconhecimento e "reputação". Uma abordagem mais naturalista poderia propor que disputas aparecem porque a ciência é pública e, não raro, vários cientistas estão em posição de apresentar avanços semelhantes. Mas, adverte Bloor, as "descobertas" envolvem mais do que achados empíricos acidentais, envolve interpretação e reinterpretação teórica. E os componentes teóricos da ciência fornecem os termos para que os cientistas percebam as próprias ações e as de outros. A descrição das ações envolvidas em uma descoberta é que pode se tornar problemática quando a descoberta é importante. Compreender isto pode requerer refinamentos da generalização inicial; exige reflexão sobre o modo como interagem e se desenvolvem as descobertas empíricas e os modelos teóricos. Bloor procura nos mostrar, assim, como esse tipo de questão tem sim relações com a natureza da ciência.

\section{DE NOVO O EMPIRISMO}

Como dito anteriormente, Bloor entende que há grandes perigos ao se atentar para as imperfeições do empirismo sem exibir suas virtudes. Para ele, esses perigos giram em torno da questão da confiabilidade da percepção sensorial e da adequada análise que a sociologia do conhecimento precisa fazer com relação a casos de percepção errônea na ciência.

A percepção errônea, para ele, tem atraído a atenção dos sociólogos, pois oferece um caminho atraente para abordar os fatores sociais na ciência. Isto é legítimo e de grande valor, mas não deve ser a questão principal da análise sociológica, argumenta Bloor, sob pena de deixar de lado o papel fundamental na ciência dos procedimentos, controles e práticas experimentais.

Para a sociologia da ciência, a confiabilidade sensorial é muito importante e há uma interação entre percepção e memória que precisa ser elucidada, na visão de Bloor. Os cientistas são "treinados" de determinadas formas, seus interesses, expectativas e compromissos teóricos têm uma dada estrutura. Em função disso, muitas vezes, alguns eventos não suscitam respostas, isto é, os cientistas não veem (ficam cegos) nenhum padrão ou ordem em suas experiências. Pode também ocorrer que diferentes cientistas interpretem diferentemente o mesmo fenômeno. Uma possível explicação sociológica para isto é que diferentes teorias levam o cientista a ter diferentes expectativas. Muitos cientistas não veem coisas que contradizem sua teoria. É como se resistissem a novas ideias e teorias ou a abordagens e técnicas pouco usuais. Embora não seja esta uma regra, isto viola o ideal científico de "manter a mente aberta". Há estudos de caso sociológicos, aponta Bloor, que mostram que a "cegueira" é uma característica constante na ciência e têm fontes identificáveis como, por exemplo, os compromissos teóricos e metodológicos, as reputações profissionais, a especialização, etc. $\mathrm{Na}$ verdade, certas características da ciência que são valiosas ou funcionais em alguns aspectos, mostram-se nocivas em outros. Isto 
sugere que parte da percepção errônea é consequência do mesmo processo que impulsiona a ciência, é normal (ibid., p. 48) e inevitável.

Bloor ilustra este ponto com as tarefas de reconhecimento de sinais.

O problema é detectar um sinal com base em ruídos de fundo; por exemplo, um ponto débil em uma confusa tela de radar. A tendência para decidir se um sinal foi de fato visto está relacionada de modo estrito às consequências conhecidas da decisão. Se os indivíduos efetivamente percebem um sinal, é algo que depende de saberem ou que é importante não perder nenhum sinal, ou que é vital nunca emitir um alarme falso. Ao variar tais parâmetros, produzem-se diferentes padrões de percepção ou de percepção errônea. O importante é que as tentativas de reduzir o número de alarmes falsos inevitavelmente levam à perda de sinais. Tentativas de nunca perder um sinal inevitavelmente ocasionam alarmes falsos (ibid., p. 49).

Para Bloor, há uma permuta entre diferentes tipos de percepção errônea que é resultado da matriz social de consequências e significados no interior da qual a percepção ocorre. Isto quer dizer que a percepção errônea está associada à organização psicossocial da ciência. Mas há também outros fatores, como falha ou fragilidade da memória (esta assumida como uma faculdade psicológica). Por exemplo, uma imagem mnemônica distorcida pode levar o cientista a desprezar uma evidência que se encontra debaixo de seus olhos. Tudo isto, segundo Bloor, mostra o quanto é difícil criticar a percepção sensorial.

Defende que é razoável sustentar que a percepção sensorial é confiável (embora o envolvimento da memória seja sempre passível de suspeição). A correta concepção experimental, o uso de instrumentos e grupos de controle (para evitar colocar o observador na posição de ter que realizar discriminações difíceis ou juízos precipitados), a prática de confrontar uma amostra com o controle, de fazer uso de condições e precauções padronizadas pela tradição técnica experimental (para que o testemunho dos sentidos possa ser uniforme e independente de teorias), o cuidado para evitar uma proporção desfavorável entre sinal e ruído, o rigor em esgotar procedimentos padronizados. Tudo isto é relembrado por Bloor para que os sociólogos não subestimem, em suas análises, a confiabilidade e a reprodutibilidade da base empírica.

Os estudos de caso mostram, segundo sua visão, não o quanto a percepção sensorial é incerta ou que ela seja uma função de nossos desejos ou compromissos teórico-metodológicos, mas o quanto a ciência é exigente no tocante à adoção dos procedimentos padronizados (ibid., p. 54).

A experiência é admissível à medida que seja pública, impessoal e passível de repetição. Mas, atrelar o conhecimento a esses aspectos da nossa experiência é uma norma social; outras formas de conhecimento têm outras normas.

\section{EXPERIÊNCIA E CRENÇA}

Para Bloor, o pressuposto de que nossa percepção é relativamente estável e garante que nossas respostas ao mundo natural sejam constantes mostra o quanto o 
empirismo é valioso, mas ele concorda com a maioria das críticas contemporâneas ao empirismo: o testemunho de nossos sentidos, por si só, não constitui o conhecimento.

A experiência sempre atua sobre um estado de crenças anterior. A experiência influencia a crença anterior, mas, em analogia com um sistema de forças, não determina a força resultante (ou crença resultante), isto porque nenhum padrão de alterações de experiências determina, por si só, um único padrão de alteração de crença. Nesse processo a componente social é clara e irredutível. Processos sociais como a educação e a formação devem ser invocados (e.g. a ciência normal kuhniana) a fim de explicar a inclusão e distribuição das crenças anteriores.

Bloor reflete sobre o fato de o empirismo ter caído em desgraça na filosofia da ciência tradicional, mas defende que os sociólogos devem explorar quaisquer ideias que lhes sejam úteis para, com elas, erigir construções adequadas. Nesse sentido, entende que a versão do empirismo assumida pela sociologia do conhecimento é, na verdade, uma teoria psicológica. Afirma ele que nossas faculdades de percepção e pensamento são coisas distintas; que a percepção atua sobre o pensamento mais do que o pensamento influencia a percepção (ibid., p. 58). Em termos da filosofia contemporânea, significa que a tese psicológica alega a existência de duas linguagens distintas: a linguagem dos dados e a linguagem teórica. Contudo, adverte Bloor, tem sido questionada a "certeza absoluta" das crenças derivadas da experiência.

Argumenta que o que importa para o estudo naturalista pretendido pela sociologia do conhecimento é poder contar com a imagem vigorosa do papel da experiência sensorial. Uma sociologia consistente não poderia jamais apresentar o conhecimento como uma fantasia sem relação com nossas experiências do mundo material que nos cerca (ibid., p. 59). A ideia é que se temos a propensão de aprender uns com os outros, temos que ter a habilidade de aprender sobre as regularidades do mundo real também. Todos os relatos sociológicos da ciência pressupõem, no entanto, confiar que podemos reagir ao mundo através de nossa experiência; nossa interação causal com o mundo é útil e permite construir explicações. O materialismo e a experiência sensorial estão, assim, na base da sociologia da ciência.

Ocorre que a forma como o mundo material se comporta não interfere no caráter causal e simétrico das explicações pretendidas pela sociologia do conhecimento. Aqui Bloor revisita o conceito de verdade, como se passará a abordar.

\section{VERDADE, CORRESPONDÊNCIA COM A REALIDADE E CONVENÇÃO}

Quando falamos em verdade é comum pensarmos que queremos dizer que alguma crença, julgamento ou afirmação corresponde à realidade e que ela capta como as coisas no mundo são, isto é, que há uma correspondência entre o conhecimento e a realidade da qual ele depende. Para Bloor, a definição de verdade é difícil de fazer e, por isso, seu caminho é o de explorar como essa noção funciona na prática. Busca mostrar que este conceito é subjetivo utilizando como exemplo a teoria do flogisto.

O flogisto foi preliminarmente identificado com o gás que hoje chamamos hidrogênio. Os químicos do séc. XVIII sabiam preparar esse gás, mas sua visão sobre ele era muito diferente da nossa (p. 65). Acreditavam que o flogisto era absorvido por uma substância que denominavam "minium" ou "cal de chumbo" 
e que quando o flogisto fosse absorvido pelo minium transformava-se em chumbo. Joseph Priesley construiu um experimento para demonstrar essa teoria. Utilizou um tubo de vidro invertido e cheio de flogisto que foi emborcado em uma cuba com água, sendo que sobre a água flutuava um cadinho com um pouco de minium. Este foi aquecido por uma luz concentrada através de uma lente e o resultado foi que o minium transformou-se em chumbo absorvendo o flogisto. Como demonstração dessa absorção, o nível de água no tubo subiu. A experiência mostrava que a teoria correspondia à realidade, se não fosse o fato de que algumas gotas de água se formaram dentro do tubo de gás. Mas como a experiência era feita sobre a água, isto poderia ser um detalhe irrelevante. Contudo, Presley decidiu refazer o experimento sobre mercúrio e observou que as gotas de água ocorriam igualmente. Diante da anomalia, sua atitude foi modificar a teoria propondo que o minium continha água. Para Bloor, um empirista poderia questionar o resultado dizendo que não foi visto o flogisto ser absorvido pelos poros do minium, que só o que se pode ver é o nível da água (ou do mercúrio) subir.

Mas não há experiência alguma que nos permita ver o gás. Assim, a correspondência da realidade com a teoria não pode ser "vista" diretamente. O que se toma como indicador de verdade é se a teoria funciona, isto é, se se pode manter uma relação de funcionamento (da teoria) com previsões bem-sucedidas. Isto, para Bloor, mostra uma correspondência não da realidade com a teoria, mas da teoria com ela mesma. O que é testado é a consistência interna da teoria.

Como explicaríamos hoje esse experimento?

Não diríamos que o flogisto foi absorvido pelo minium ou que a água surgiu do minium. Diríamos que o gás no tubo é hidrogênio e que o minium é óxido de chumbo. Ao aquecê-lo o oxigênio se desprende do óxido e deixa o chumbo. Esse oxigênio combinase então com o hidrogênio e forma água. Durante essa reação o gás é consumido, o que eleva o nível, ou de mercúrio ou de água, no tubo de gás. (ibid., p. 67).

Em outras palavras, veríamos exatamente o que Presley viu, mas com uma concepção teórica muito diferente. Da mesma forma, não teríamos acesso aos aspectos ocultos da realidade, isto é, não poderíamos ver o gás e a reação ocorrendo de forma direta. Nossa teoria estaria plenamente justificada porque sua coerência interna pode ser mantida em um número maior de experiências teoricamente interpretadas.

Assim, argumenta Bloor, a relação de correspondência entre realidade e teoria é vaga porque não temos o acesso necessário à realidade para poder confrontá-la com nossa teoria. Tudo o que temos, e tudo o que precisamos são nossas teorias e nossa experiência do mundo, nossos resultados experimentais e interações sensório-motoras com objetos manipuláveis (p. 68).

Daí a importância dos sentidos, pois o pensamento científico pode prosseguir com base nos nossos princípios internos de avaliação. Estes são impulsionados com a percepção do erro quando ele eclode em elementos de nossas teorias, propósitos, problemas e padrões. Se não tivéssemos a intenção de obter teorias mais gerais poderíamos ter permanecido com a explicação de Presley. 
Tudo isso coloca, no entanto, um problema à noção de verdade. A verdade, para Bloor, é uma terminologia conveniente que surge naturalmente e tem várias funções. Uma delas é a função discriminatória, pois temos a necessidade de ordenar nossas crenças, distinguir aquelas que funcionam daquelas que não funcionam, distinguir o "verdadeiro" do "falso". A segunda função é retórica, isto é, a verdade, a adequação, o acordo cumprem um papel na argumentação, na crítica e na persuasão. Dito de outra forma, nosso conhecimento não está sob o controle apenas dos estímulos do mundo físico; há sempre um componente social em nosso conhecimento.

É porque queremos colocar um ponto de interrogação em tudo aquilo que desejamos pôr em dúvida, modificar ou consolidar que falamos em verdade. Invocamos a verdade para recomendar esta ou aquela alegação, ou para distinguir algo de qualquer opinião recebida. Verdade, então, é pensada como algo que transcende à mera crença. Para Bloor, a linguagem da verdade estava tão legitimamente disponível a Presley, com sua teoria do flogisto, quanto a nós.

Lançamos mão da verdade e da falsidade para selecionar crenças, para afirmar a autoridade, relacionando as crenças com um ambiente externo de causas.

Se o trabalho de um cientista resulta em algo que pode ser reproduzido, se for reprodutível em determinadas circunstâncias, então aceitamos facilmente que podemos utilizar a linguagem da verdade para distingui-lo de outro que não tem o mesmo êxito, ainda que as condições não lhe sejam favoráveis. Isto, propõe Bloor, realça circunstâncias causalmente relevantes e suas relações com propósitos e preferências culturais.

Para ele, as teorias científicas, os métodos e os resultados são convenções sociais. Mas afirma estar consciente da oposição que esta assunção sofre porque, em geral, se algo é uma convenção então é “arbitrário". Defende que convenções não são arbitrárias. Nem tudo pode tornar-se uma convenção (ibid., p. 73). Seria uma tolice, assevera, pensar que convenções são coisas que podem ser trivialmente satisfeitas. Tudo aquilo que pode se tornar convenção, ou norma, ou instituição é condicionado pela credibilidade social e utilidade prática.

Destaca que o "programa forte" também assume a linguagem da verdade e da falsidade, mas o faz de uma forma muito diferente: não avalia para distinguir verdade da falsidade e não as subordina a diferentes estilos de explicação (não usa explicações causais só para o erro, usa-as para a verdade também); concorda que as teorias têm que funcionar com alto grau de precisão dentro do âmbito que convencionalmente se espera delas: teorias devem fazer previsões bem-sucedidas. Trata-se de uma severa disciplina à qual submetemos nossa constituição mental, mas não deixa de ser uma convenção.

Para Bloor, convenções não são autoevidentes, nem universais ou estáticas. As teorias e os procedimentos científicos têm de ser consoantes a outras convenções que prevalecem em um grupo social, encontram um problema "político" de aceitação como qualquer outra recomendação política. A aceitação de uma ideia por um grupo social não a torna verdadeira, nada há no conceito de verdade que permita a crença tornar verdadeira uma ideia. Mas a aceitação pode torná-la base para seu entendimento e sua adaptação ao mundo. É nesse sentido que o conhecimento científico, seus métodos e resultados, repousa sobre uma forma de consenso social, mas não são "meras" convenções sociais, no sentido 
de não serem exigências por natureza. Ao contrário, as exigências convencionais nos forçam a limites extremos de nossas capacidades física e mental (ibid., p. 75).

\section{UMA ABORDAGEM DURKHEIMIANA DA CIÊNCIA}

Os argumentos até aqui abordados buscam mostrar que os métodos da sociologia do conhecimento em nada podem excluí-la da ciência, pois são tipicamente aceitos pela própria ciência. Mas, afirma Bloor, pode ter ficado a sensação de que a "verdade foi reduzida à mera convenção social". Este ponto precisa ser retomado, alerta ele, para explicar sua presença, pois isto pode revelar algo sobre a natureza da ciência.

Em primeiro lugar, Bloor pensa que se a análise sociológica não pudesse ser aplicada exaustivamente à ciência, significaria que a ciência não poderia conhecer a si mesma do ponto de vista científico e isto revelaria uma estranheza no âmago de nossa cultura. Significaria que outros elementos da nossa cultura podem ser conhecidos pela ciência, mas a própria ciência não, o que faria da ciência um caso especial.

Para ele isto suscita uma questão: como pode parecer correto e apropriado fazer da ciência uma exceção a ela própria quando a generalidade irrestrita parece tão obviamente desejável? (ibid., p. 77). Para tentar entender essa feição de nossas atitudes culturais, Bloor recorre à obra de Durkheim (1915) intitulada "As formas elementares da vida religiosa”, que faz uma analogia entre ciência e religião.

Para Durkheim a principal característica dos fenômenos religiosos é que eles supõem uma separação bipartida do universo: as coisas sagradas e as profanas. As coisas sagradas são aquelas que as interdições protegem e isolam. As coisas profanas, aquelas a que se aplicam as interdições e que devem permanecer à distância das primeiras (DURKHEIM, 1915, p. 56 apud BLOOR, 2009).

A noção intrigante com relação à ciência (como algo especial) seria explicável, argumenta Bloor, se ela fosse tratada como algo sagrado, algo a ser mantido a uma distância respeitosa. Se assim fosse, teríamos que presumir que os princípios da ciência são incomparáveis àqueles que operam no mundo profano, por exemplo, da política e do poder. Isto explicaria, para ele, porque alguns filósofos e cientistas não consideram a sociologia como parte da ciência: ela pertenceria ao profano.

Considerar a ciência como algo sagrado leva-nos de volta à metáfora ciência e religião. Para Durkheim, a religião é essencialmente uma fonte de força; quando as pessoas se comunicam com seus deuses, elas se fortificam e protegem a si mesmas e isso pressupõe que as pessoas sejam constituídas por duas partes, alma e mente (esta associada ao corpo). A alma é aquilo que participa do sagrado e é, em natureza, diferente do corpo; a mente pertence ao profano e precisa ser controlada. Esta dualidade é similar àquela que aparece na ciência, por exemplo, teoria e prática, fundamento e rotina, etc. Por esta metáfora, as realizações e o conteúdo mais puro da ciência seriam o que há nela de sagrado, algo pode ser pensado como se guiasse e informasse as partes menos vitais, as rotinas, as aplicações, as formas externas da técnica e do método. Estes aspectos nunca devem ser considerados autossuficientes a ponto de poder esquecer a necessidade de obter sua força de uma fonte de natureza distinta e mais poderosa. 
Durkheim coloca a tese de que a religião é essencialmente um modo de perceber a sociedade na qual vivemos e de tornar inteligível a experiência que temos com ela; é um sistema de ideias no qual os indivíduos representam a si a sociedade da qual são membros. Uma vez que é por vias espirituais que a pressão social se exerce, ela não poderia deixar de dar aos homens a ideia de que, fora deles, existe uma ou diversas forças das quais dependem tanto morais quanto, concomitantemente, eficientes (DURKHEIM, 1915, p. 239 apud BLOOR, 2009, p. 84).

Essa imagem é poderosa, argumenta Bloor, e pode ser suposto que quando pensamos sobre a natureza do conhecimento estamos manipulando imagens da sociedade, estamos refletindo sobre princípios segundo os quais a sociedade está organizada. Assim como a religião transforma nossa experiência da sociedade, também os filósofos e epistemólogos o fazem ao refletir sobre a natureza do conhecimento. E caso Durkheim esteja certo, afirma Bloor, a sociedade tende a perceber-se como sagrada (p. 85). Assim, a ciência (que faz uso de imagens sociais) seria sagrada e deve ser mantida em separado, "reificada", "mistificada" para se proteger do profano que destruiria sua eficiência.

Contudo, pensar sobre o conhecimento por meio de manipulações de imagens da sociedade nem sempre é um processo consciente, adverte Bloor. Refletir sobre a natureza do conhecimento é mergulhar em um processo obscuro porque o conhecimento é algo abstrato, difícil de ser pensado diretamente e daí a necessidade de usar modelos sociais. Mas há outros motivos, para Bloor existem conexões intuitivas entre conhecimento e sociedade. O conhecimento deve ser obtido, mantido, organizado, distribuído e todos esses processos são associados a instituições sociais estabelecidas: o laboratório, a universidade, o escritório, a igreja, a escola; a mente registra, em algum nível, a relação entre conhecimento e autoridade e poder.

Para tentar demonstrar que os relatos sobre o conhecimento científico usam imagens de um mundo social, Bloor examina dois casos particulares, isto é, faz um estudo de caso sobre duas teorias do conhecimento modernas e suas relações com as metáforas e as imagens sociais: o debate de Karl Popper e Thomas Kuhn.

Popper (2000) tem uma posição clara de que devemos construir hipóteses e/ou teorias poderosas para tentar alcançar a verdade sobre o mundo; as teorias derivam de teorias prévias; somos livres para usar o mito, o preconceito, o palpite; e uma vez formulada, a conjetura deve passar pelo escrutínio lógico e empírico; a ciência exige esforço crítico e é um empreendimento sem fim. Para Bloor, o estilo da filosofia da ciência de Popper usa a metáfora da "luta darwiniana" pela sobrevivência e eliminação de teorias mais fracas. A diferença é que na ciência são nossas teorias que morrem por nós. Do ponto de vista social, a imagem é antiautoritária, pois não há fonte privilegiada de verdade, todas as hipóteses devem igualmente ser submetidas à crítica e ao teste.

Kuhn (2003) tem uma concepção de ciência também simples. Seu foco é o "paradigma", que é uma realização exemplar de trabalho científico que cria uma tradição de pesquisa em uma área específica. $O$ paradigma proporciona o modelo de trabalho, as orientações sobre o método experimental, os problemas e a interpretação teórica; os cientistas fazem variações e elaborações em torno do paradigma. As relações formam uma rede de analogias à "semelhança de famílias"; o conjunto de atividades relativamente autônomas que surgem na tradição em torno do 
paradigma é chamado "ciência normal" e Kuhn compara essa atividade à aplicação de um precedente legal na jurisprudência. Mas o processo de formação científica é apresentado como autoritário, não é uma apresentação de um relato imparcial de visões de mundo, mas sim visa tornar o estudante apto para trabalhar no paradigma. Para Bloor, o tom do relato da ciência de Kuhn é causado pelas metáforas que ele utiliza: cientistas formam uma "comunidade", o que leva à solidariedade social e insinua um modo de vida com seus próprios estilos, rotinas, hábitos.

Bloor sustenta que esses dois relatos diferentes sobre a ciência guardam uma vasta área de "terreno comum": Popper enfatiza o debate, o desacordo, a crítica, ao passo que para Kuhn as áreas de acordo são amplamente admitidas; contudo, ambos atentam para a natureza social da ciência, embora os processos sociais predominantes nos dois pensamentos sejam diferentes. Para Popper o embate é público, para Kuhn o modo de vida é partilhado; Popper enfoca aspectos da ciência universais, cânones metodológicos e valores mais gerais enquanto Kuhn aborda aspectos locais, concretos, obras específicas que oferecem exemplares para um grupo de cientistas; Popper vê a ciência como linear, seus procedimentos seriam aplicáveis a todos os seus períodos, enquanto Kuhn mantém uma concepção cíclica. Um popperiano olha para o futuro, um kuhniano trabalha segundo precedentes, referenciado no passado (BLOOR, p.99).

Argumenta Bloor que o embate Popper versus Kuhn representa um caso de oposição que ele compara à clássica oposição de "ideologias iluminista e romântica". Neste ponto ele aborda ideias de Mannheim (1953) e afirma que a ideologia iluminista recorre à noção de "contrato social" (o mito do "estado de natureza" pré-social, um estado mais ou menos brutal em que a sociedade teria que libertar o ser humano assegurando-lhe direitos como a vida, a liberdade, a propriedade). O pensamento "romântico", de outro lado, não encontra lugar para direitos naturais, contratos sociais ou estados de natureza - a noção de natureza pré-social é substituída pela noção de uma natureza social. Para esta ideologia é a sociedade quem é natural. A harmonia garantida pelo contrato social é substituída por imagens orgânicas da unidade familiar, segundo a qual, direitos, deveres, obrigações e autoridade não devem ser distribuídas uniformemente, mas sim, de acordo com a geração, a função e a posição social.

Os estilos romântico e iluminista podem ser comparados, assim como comparáveis são as epistemologias de Popper e Kuhn. O romântico não é atomista ou individualista, não vê a sociedade como uma coleção de indivíduos, mas como detentora de espírito, tradições e estilos característicos; nele o concreto e histórico são mais importantes que o universal e atemporal, que pertence ao estilo iluminista.

Desta forma, Bloor busca mostrar a existência de uma identidade estrutural entre dois estereótipos sociais e duas posições opostas na filosofia da ciência (Popper versus Kuhn). Isto fica mais claro nas palavras do próprio autor:

É fácil demonstrar que Popper deve ser classificado como um pensador iluminista e Kuhn, como um pensador romântico. Popper é individualista e atomista ao tratar a ciência como uma coleção de teorias isoladas. Pouca atenção é dispensada às tradições de construção de teorias, às continuidades entre tradições ou às descontinuidades entre diferentes épocas da ciência. (...). Os aspectos românticos de Kuhn são também muito 
claros. As ideias científicas individuais são sempre parte do "todo" abrangente de uma tradição de pesquisa. Os aspectos comunitários da ciência são proeminentemente marcados e com eles está o caráter autoritário do processo educacional (...) o tom descritivo do relato de Kuhn, no qual o conteúdo prescritivo se encontra implícito e não explicitado, também se coaduna com o estilo romântico (ibid., pp. 102-104).

Em relação aos fatos, diz Bloor, tanto Popper quanto Kuhn são mais céticos que o senso comum, isto é, ambos acreditam na natureza "teórica" dos fatos. Qualquer relato de um resultado experimental tem o mesmo status lógico da hipótese que possa vir a ser testada no sentido de que os enunciados observacionais são, sem dúvida, sugeridos pela experiência, mas a experiência é apenas um fato sobre a causa da nossa aceitação de uma hipótese. Destaca que embora Popper e Kuhn expressem posições distintas sobre o conhecimento, Popper é mais prescritivo, ao passo que Kuhn é mais descritivo; ambos são prescritivos e descritivos em níveis e estilos distintos. Popper enfatiza o debate, o desacordo e a crítica enquanto para Kuhn o acordo é amplamente admitido, mas ambos atentam para a natureza social da ciência (ibid., p.98). Com esse estudo de caso Bloor busca mostrar a existência de uma similaridade estrutural entre dois estereótipos sociais e políticos (iluminista e romântico) e duas posições opostas na filosofia da ciência contemporânea. Tenta apresentar pontos de contato entre posições sociais e epistemológicas; a hipótese por ele aventada para explicar essa similaridade é de que as teorias do conhecimento são, na realidade, reflexos de ideologias sociais e que há, portanto, uma transferência de ideias do domínio social para o epistemológico. E mais, que essa conexão é uma consequência natural do modo como vivemos e pensamos. O que pode parecer ao filósofo a análise pura desses conceitos, ou o apelo imaculado ao seu significado, ou a mera exibição de suas implicações lógicas, será, na verdade, a repetição de parte das experiências acumuladas de nossa época (ibid., p. 119).

\section{A NEGOCIAÇÃO DE UMA PROVA NA MATEMÁTICA}

Bloor argumenta que mesmo na Matemática negociações criam significado e que os limites de nossos conceitos não são mais descobertos que os limites de nossos países ou os conteúdos de nossas instituições (ibid., p. 218).

Neste ponto, recorre a um exemplo. Euler, em 1752, notou que se tomarmos um cubo ou uma pirâmide e contarmos os vértices $(V)$, o número de arestas (A) e o número de faces (F) eles satisfazem à fórmula $V-A+F=2$. Após examinar vários poliedros, Euler percebeu que a fórmula funcionava e, acreditando que era verdadeira para todos os poliedros, sentiu-se justificado a chamar o resultado de teorema. Hoje em dia, afirma Bloor, um resultado assim seria considerado detentor de não mais que uma certeza indutiva ou moral (p. 219) e que um teorema genuíno deve possuir uma prova. A imagem usual de uma prova é de que ela dota o teorema de certeza e de um caráter definitivo. Isto, afirma ele, parece colocar os teoremas matemáticos fora do alcance sociopsicológico, mas Lakatos (1962) abriu um debate sobre o teorema de Euler. E, em 1813, Cauchy buscando validar o teorema, propôs um "experimento mental" imaginando que 
os poliedros fossem feitos de folhas de borracha e que uma de suas faces pudesse ser removida, sendo, então, a soma de $\mathrm{V}$, A e F feita com o valor de F reduzido de um o que levaria a $V-A+F=1$. Mas dado que uma das faces é removida é possível imaginar a figura aberta e achatada em um plano; o passo seguinte é desenhar linhas diagonais nas formas achatadas transformando as superfícies em conjuntos de triângulos; ao acrescentar uma aresta para formar um triângulo A e F são acrescidos de 1 ; cada nova aresta cria uma face de forma que $V-A+F$ permanece inalterado; o próximo passo é remover um a um os triângulos e a cada triângulo removido perceber que uma $\mathrm{A}$ e uma $\mathrm{F}$ desaparecem mantendo inalterada a fórmula; assim fazendo, todas as operações deixam a fórmula inalterada e podese argumentar que "se a fórmula de Euler é válida para o poliedro original, então $V-A+F=1$ deve ser válida para o triângulo que sobra quando todos os outros forem removidos". Então a fórmula original pode ser validada.

Bloor argumenta que a questão geral da prova é que ela mostra como a propriedade percebida por Euler é uma consequência natural de um triângulo ter três ângulos, três lados e uma face e o experimento mental foi um modo de ver o poliedro como formado por triângulos. Assim, o trabalho da prova consiste em tornar um "fato surgido da inspeção" e assimilá-lo em um esquema bem conhecido. Ou seja, o modelo de achatar e triangular recorre à experiência (p. 222). Em outras palavras, elementos de nossa experiência tornam um fato intrigante em algo manifesto com uso de um esquema simples. Ocorre que provas como a de Cauchy colocam outras questões: todos os poliedros podem ter uma face removida e serem esticados como exige a prova? A triangulação produz sempre uma nova face a cada nova aresta?

Bloor diz que em 1812, Lhuilier, e em 1832 Hessel, indicaram ambos uma exceção ao teorema de Euler e à prova de Cauchy, tendo, então, havido contraexemplos. Isto coloca a questão de decidir se a prova não é realmente uma prova ou se o contraexemplo não é, de fato, um contraexemplo, o que remete à revisão da definição de poliedro, apresentada por Legendre em 1794. Várias propostas surgiram como definição de poliedro o que resultou em uma limitação da prova que foi enunciada da seguinte forma: "para todo o poliedro simples, $V-A+F=2$, onde "simples" significa que ele pode ser achatado".

A análise desse exemplo revela que, afirma Bloor:

O teorema veio ao mundo como uma generalização indutiva. Uma prova foi apresentada e isso expôs a generalização à crítica no próprio ato de mostrar por que ela teria que ser verdadeira. Contraexemplos revelaram que não estava claro o que era e o que não era um poliedro. O significado do termo "poliedro" precisava de uma definição, pois era completamente indeterminado na zona de penumbra revelada pelos contraexemplos. Teve que ser criado ou negociado. (ibid., p. 225, grifo nosso).

Assim, foi elaborada, com base no conflito e em negociações, uma complicada estrutura de definições para consolidar a prova e o âmbito do teorema. Essas definições refletem os propósitos daqueles que as forjaram, entram em jogo tipos de figuras e quais aspectos das figuras são considerados importantes e interessantes. Esse procedimento, alerta ele, não torna as provas inúteis, pois como dito por Lakatos a prova é um recurso valioso, mas a torna semelhante 
a modelos físicos; estes estabelecem a pretensão de compreender as coisas à luz de modelos que permitem fazer analogias. O que Lakatos (1962) pretendeu ao questionar esse exemplo foi mostrar que a Matemática, como em qualquer outra ciência, faz uso de conjecturas e refutações, que não há certezas absolutas. Para Lakatos o caráter autoevidente por vezes alegado para os axiomas dos sistemas formais, assim como os passos intuitivos triviais dos raciocínios que levam aos resultados são meras ilusões; sua análise também argumenta que há paradigmas na Matemática, períodos de estagnação em que certos estilos de argumento têm aparência de verdades eternas, de que seus pressupostos não são progressistas.

Para Bloor, toda essa discussão revela um processo subjacente a respeito dos processos mentais e sociais. Mostra que as pessoas não são governadas por suas ideias ou conceitos; que mesmo na Matemática, o mais cerebral de todos os empreendimentos, são pessoas que governam as ideias. As ideias são construídas de modo que sejam passíveis de extensão, ou seja, os usos futuros, os significados expandidos não estão presentes na forma embrionária, nada há de escondido nos conceitos que os impeça de seguir, no futuro, outro caminho. A extensão dos conceitos pode surgir de fatores em operação na situação e estes fatores, ou forças, podem ser diferentes para pessoas diferentes, dependendo de sua experiência passada. É no âmbito de operação desses fatores que, para Bloor, entra em jogo o papel criativo da negociação. Isto aumenta a necessidade de uma perspectiva sociológica. Para ele, a crença de que o papel das ideias no comportamento exclui fatores sociais como causas é superficial.

\section{O DEBATE SOBRE O PROGRAMA FORTE DA SOCIOLOGIA DO CONHECIMENTO}

No posfácio a edições posteriores a de 1976 de seu livro Conbecimento e imaginário social, Bloor comenta várias críticas de sociólogos que o consideram "sociologicamente irrelevante" (BEN-DAVID, 1982, p. 46, p. 54 apud BLOOR, 2008); de antropólogos que o entendem como "sociocêntrico" e incompatível com a "unicidade" da natureza humana (ARCHER, 1987, p. 236 apud BLOOR, 2008); de cientista cognitivos que o acusam de "reciclador de clássicos... equívocos manualescos" (SLEZAK, 1989, p. 571 apud BLOOR, 2008). Bloor considera que essas polêmicas animam a tediosa rotina da investigação acadêmica (ibid., p.241) e que várias dessas críticas podem ser atribuídas a estereótipos emotivos que não compreendem que o significado do postulado da simetria é o de que nossas melhores e mais relevantes realizações científicas não poderiam existir como tais se não tivessem o caráter de instituições sociais; são influenciadas socialmente e são sociologicamente problemáticas como quaisquer outras instituições.

Bruno Latour (1994) considera vantajoso o que ele chama de "primeiro princípio de simetria" defendido por Bloor, defendendo que se usem os mesmos critérios para determinar o que é verdadeiro e o que é falso, não mais distinguindo a priori entre crenças e ideologias e conhecimento científico. Mas, acusa que o conceito de simetria, como proposto, leva a um impasse, pois se mostra assimétrico ao atribuir à sociedade a responsabilidade e autoridade para determinar o que é falso e verdadeiro e, embora não negue a realidade, retira da natureza a autoridade de determinar seus próprios fatos ("matters of facts"), isto é, de determinar a verdade 
científica (LATOUR, 1994, pp. 93-94). Ele invoca os quase-objetos (ou "híbridos") e defende que seria possível determinar quais elementos são de ordem natural e quais são de ordem social através de um processo denominado "purificação" e discorre sobre sua proposta para delimitar o científico do "proscrito".

A resposta de Bloor (1999b) é de que há nos escritos de Latour tensões não resolvidas: "Há um abismo entre nós, o que me torna 'totalmente incompetente' ( $p .121)$ para criticar o seu trabalho (referindo-se a Latour), mas, aparentemente, deixa-o totalmente livre para criticar o meu’. Os principais pontos do embate, são para Bloor: Latour ataca o programa forte da sociologia do conhecimento e afirma ter detectado falhas profundas na estrutura pensada por Bloor e, por isso, propõe uma abordagem nova construída em princípios muito diferentes. Um argumento utilizado por Bloor em um artigo intitulado Anti-Latour (BLOOR, 1999a), é que submetidas a um detalhado escrutínio as pretensões de Latour colapsam: primeiro porque sua compreensão do "programa forte" é equivocada e as alegadas falhas são produto de seu engano; segundo, a alternativa que ele propõe ("nova abordagem") é incoerente e insustentável, pois descarta todos os objetivos explicativos e causais do programa forte da sociologia do conhecimento, embora Latour alegue conhecêlos de "dentro para fora", por ter traduzido para o francês o livro de Bloor. Durante anos ele espalhou desinformação a respeito do programa forte, afirma Bloor. Por exemplo, Latour acusa-o de nunca ter estado em um laboratório como observador sociológico ao que Bloor replica dizendo que, como investigador, fez inúmeros experimentos no laboratório; mas não são as credenciais de trabalho de campo de Latour que ele questiona (reconhece que Latour, de fato, realizou estudo etnográfico (LATOUR, 1997)), e sim suas interpretações. Argumenta que assim como um físico teórico pode detectar variáveis não controladas em um experimento sem sujar suas mãos, as diferenças entre eles não estão em áreas onde uma visita ao laboratório possa fazer a diferença.

Latour, argumenta Bloor, coloca ênfase em como os cientistas trabalham duro para dar maior credibilidade às teorias, mas seu erro é considerar que o relativismo do "programa forte" e o princípio de simetria significam que todas as teorias podem ter a mesma credibilidade. Isso não acontece. Discorda também do entendimento de Latour de que a tese da indeterminação é o mesmo que a alegação de que a experiência do mundo e os objetos nele existentes "não faz diferença". Isto está errado, porque a riqueza do mundo natural e a complexidade do envolvimento do cientista com ele é fundamental para a tese da indeterminação (e para o "programa forte"), quando devidamente compreendida. A sociedade, defende Bloor, está implicada no nível mais fundamental de nossa compreensão do mundo material. Referenciais sociais fornecem os padrões normativos que definem "o certo e o errado" que se aplica a todos os conceitos, incluindo aqueles que se referem aos objetos que nos rodeiam; constituem as regras para o uso dos conceitos sem as quais não se pode dizer que os conceitos tenham propriamente um conteúdo. Desta forma, a autorreferência torna-se parte integrante de referência externa. Estas são as ligações que escaparam a Latour, argumenta Bloor.

$\mathrm{O}$ autor responde também às críticas feitas por Stephen Kemp que alega que o programa forte deve ser rejeitado por três razões: primeiro, ele incorpora um "idealismo fraco", isto é, os seus apoiadores efetivamente cortam a ligação 
entre linguagem e o mundo; em segundo lugar, contesta as razões que os cientistas oferecem na explicação de suas próprias crenças; terceiro, ele destrói a distinção entre ação instrumental bem e mal sucedida.

Minha esperança, diz ele, é que cuidadosa exegese irá compensar as inúmeras interpretações erradas que estão em curso na literatura, em que especial atenção é dada ao que é dito sobre os padrões normativos envolvidos na aplicação de conceitos; a operação dessas normas em face da negociabilidade de todos os conceitos é explorada e é causa de mal-entendidos.

Bloor (2007) afirma que o programa em geral recomendado por vários filósofos da ciência contemporâneos trata a sociedade como algo que, se entra no conteúdo do conhecimento, prejudica o funcionamento da razão e atenua a relação com o meio material. A sociedade teria um papel de mero facilitador ou inibidor, mas nenhum papel constitutivo. Para Bloor, o que Kemp faz em seu artigo "Salvando o Programa Forte" é tentar empurrar a dimensão convencional e normativa para fora da análise da aplicação dos conceitos e, em segundo lugar, afirma que o processo de identificar os elementos sociais no conhecimento desafia a operação da razão. Bloor argumenta que as propriedades lógicas da rede de conceitos e o papel do social foi persistentemente identificado erroneamente ou deixado de fora e que Kemp, não intencionalmente, acaba por apoiar uma posição antissociológica de racionalistas e filósofos contra quem o programa forte tem batalhado. Entende Bloor que essas batalhas não devem ser retomadas; seria fazer o campo recuar trinta anos, um recuo à discussão Kuhn versus Popper e admite que há coisas a serem aprendidas com as críticas à sociologia do conhecimento o que, de certa forma, mantém o debate aberto.

\section{CONSIDERACְÕES FINAIS}

O que se buscou através desta análise introdutória à visão sociológica de David Bloor foi mostrar, primeiramente, que o debate em torno da natureza da ciência (sociológico, ou não) não findou, parece sustentar a mesma característica da própria ciência, isto é, não tem perguntas nem respostas finais. Em segundo lugar, teve-se por objetivo interpretar ideias do "programa forte" da sociologia do conhecimento, que tem estado presente na literatura. Como afirma Bloor, nossas atitudes cotidianas são, na verdade, práticas avaliativas e as avaliações, assim como a curiosidade, são, por natureza, assimétricas. Tipicamente coisas alarmantes, não usuais atraem nossa atenção. Então, por que não nos permitir que a sociologia da ciência possa ser debatida em sala de aula, especialmente na formação de professores de ciências?

De outro lado, aproveitando a noção de simetria, profundamente explorada por Bloor no sentido de que não apenas desvios e erros merecem análise no curso da ciência, mas também nossas teorias e concepções consideradas racionais demandam comentários, podemos (ou devemos) aplicá-la a uma reflexão da educação científica (ensino de Física e de Ciências, em geral). No ensino tradicional perseguimos e avaliamos o acerto, a resposta certa, mas a noção de simetria sugere que deveríamos adotar em relação ao erro, à argumentação inadequada para explicar conceitos e fenômenos, a mesma postura e aproveitar estas situações de sala de aula para enriquecer a compreensão dos estudantes, sem que eles precisem se sentir punidos. 
Ou seja, ensinar Física/Ciências não é privilegiar o acerto, tão somente, mas aproveitar o erro com a mesma seriedade, o problematizando e corrigindo-o para que a ciência seja percebida na sua totalidade, seus benefícios, seu papel, sua natureza (não neutra), seus erros e controvérsias. Enfim, a ciência como uma construção tipicamente humana e, consequentemente, seu ensino-aprendizagem também pode ser tomado como um processo de trocas que envolve erros e acertos. Não falamos apenas de erros (e acertos) na resolução de exercícios; também o uso de metodologias ativas (Peer Instruction é uma possibilidade (ARAUJO \& MAZUR, 2013), ensino por projetos (MASSONI, DANTAS \& BARP, 2019) ou por investigação, etc.) favorecem debates entre estudantes, promovem a argumentação, a defesa de ideias como forma de alcançar uma compreensão mais significativa e proveitosa na educação científica. Isto, contudo, pressupõe mudar muito a sala de aula atual, focando menos no professor e dando, simetricamente, a palavra aos estudantes.

Esta é uma reflexão dos nossos tempos e acreditamos que uma compreensão de ideias de Bloor pode ser útil à educação científica, além de gerar questões frutíferas à pesquisa, que tem se defrontado com desafios persistentes de como levar História e Filosofia da Ciência para as sala de aula nos diferentes níveis educacionais.

\section{REFERÊNCIAS}

ARAUJO, I. S.; MAZUR, E. Instrução pelos colegas e ensino sob medida: uma proposta para o engajamento dos alunos no processo de ensino-aprendizagem de Física. Caderno Brasileiro de Ensino de Física, v. 30, n. 2, 2013.

BERLAND, L. K. et. al. Epistemologies in Practice: making scientific practices meaningful for students. Journal of Research in Science Teaching, vol. 53, n. 7, p. 1082-1112, 2016.

BLOOR, D. Conbecimento e imaginário social. São Paulo: Editora da UNESP, 2009.

BLOOR, D. Anti-Latour. Studies in History and Philosophy of Science, v. 30, pp. 81-112, 1999a.

BLOOR, D. Reply to Bruno Latour. Studies in History and Philosophy of Science, v. 30, n. 1, pp. 131-136, $1999 \mathrm{~b}$.

BLOOR, D. Ideals and monisms: recent criticisms of the Strong Programme in the sociology of knowledge. Studies in History and Philosopby of Science, 38, pp. 210-234, 2007.

DURKHEIM, E. The elementary forms of the religious life. Londres: Allen and Unwin. 1915, apud BLOOR, D. Conbecimento e imaginário social. São Paulo: Editora da UNESP, 2009.

FORATO, T. C. M; PIETROCOLA, M; MARTINS, R. A. Historiografia e natureza da ciência na sala de aula. Caderno Brasileiro de Ensino de Física, vol. 28, n.1, p. 28-59, 2011.

KUHN, T. S. A estrutura das revolucões cientificas. São Paulo: Perspectiva, 6a ed., 2003.

LAKATOS, I. La metodología de los programas de investigación cientifica. Madrid: Alianza, 1993.

LAKATOS, I. Infinite regress and the Foundations of Mathematics. Proceedings of the Aristotelian Society, sup., v. 36, pp. 155-184, 1962. 
LATOUR, B.; WOOLGAR, S. A Vida de Laboratório: a produção dos fatos científicos. Rio de Janeiro: Relume Dumara, 1997.

LATOUR, B. Jamais fomos modernos, Rio de Janeiro: Editora 34, 1994.

MARTINS, R. A. Como Becquerel não descobriu a Radioatividade. Caderno Catarinense de Ensino de Física, 7 (Número Especial), pp. 27-45, 1990.

MASSONI, N. T.; DANTAS, C. R. S; BARP, J. A Teoria da aprendizagem Significativa articulada ao "Ensino por Microprojetos": uma possibilidade ao letramento científico. Revista Dynamis (FURB online), v. 25, n. 3, p. 52-67, 2019.

POPPER, K, R. Conjecturas e refutações. Brasília: Editora da UnB, $5^{a}$ ed., 2008

POPPER, K. R. A lógica da pesquisa científica. São Paulo: Editora Cultrix, 6ª ed., 2000.

POPPER, K. R. A miséria do historicismo. São Paulo: Cultrix, 1980.

\section{NOTAS}

1 O postulado da simetria exige que se busque o mesmo tipo de causas para crenças verdadeiras e falsas ou racionais e irracionais. Mas isto não está de acordo com o senso comum porque nossas atitudes cotidianas são práticas e avaliativas e, por natureza, assimétricas, adverte Bloor. O mesmo ocorre com a curiosidade. Tipicamente, coisas alarmantes atraem nossa atenção, pois nosso cérebro adapta-se com rapidez às condições de fundo (que consistem em regularidades sociais) e preserva a capacidade de processar informações diante de tudo o que possa romper a rotina local. Por isso nossa curiosidade é socialmente estruturada. A condição de simetria é o apelo a superar tais tendências e reestruturar nossa curiosidade (BLOOR, 2009, p. 259).

2 Este argumento é análogo ao da indução (o chamado problema da indução, POPPER, 2008, p. 77): indução que se justifica pela própria indução, isto é problemático.

Submetido em 10/01/2019

Aprovado em 13/01/2020

\section{Contato:}

Neusa Teresinha Massoni

Universidade Federal do Rio Grande do Sul - UFRGS

Av. Bento Gonçalves, 9500, Prédio 43176, Bairro Agronomia

CEP 91.509-900 - Porto Alegre, RS - Brasil 